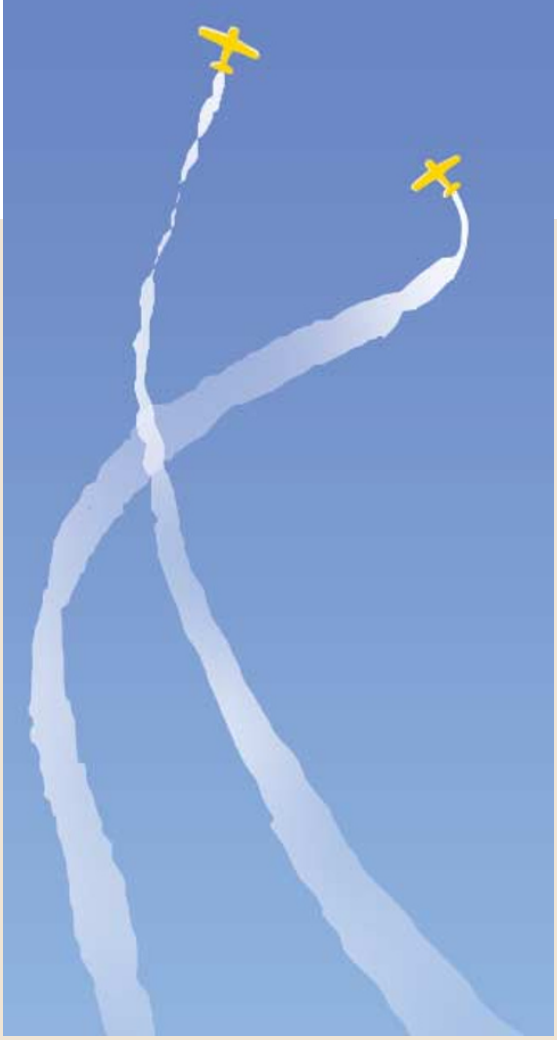
might be common to many enhancer elements - the authors used RNA fluorescent in situ hybridization (FISH) to examine its interaction with the $A b d-B$ promoter.

Confocal microscopy of D. melanogaster embryo abdominal segments - where $A b d-B$ is normally expressed - also revealed that $3^{\prime}$ region of $A b d-B$ is known to mediate this somatic pairing of homologues - the authors suggest that such elements might exist upstream of many genes and that transvection might be an important general mechanism for gene regulation in higher Metazoa.

Magdalena Skipper

\title{
REPRODUCTION
}

\section{Family planning the ant way}

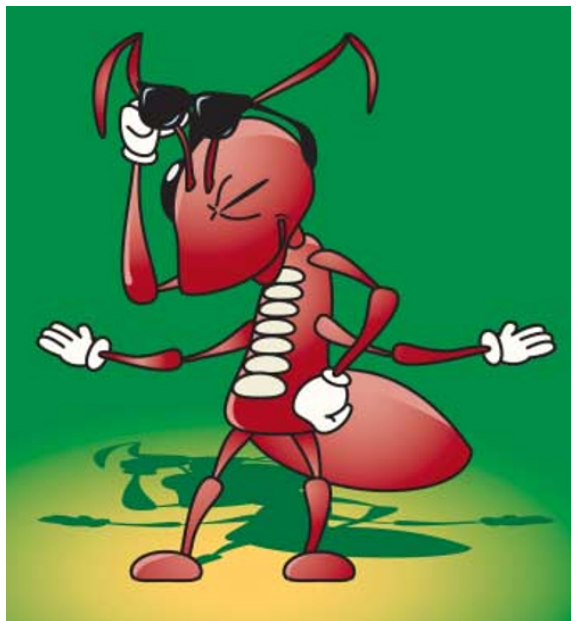

As a reproductive strategy, sex has its pluses and minuses: it ensures genetic diversity but, unlike asexual reproduction, it means that parents pass on only $50 \%$ of their genes. Reporting in Science, Morgan Pearcy and colleagues show how the habits of one species of ant allow it to use a combination of both reproductive solutions to maximize advantage.
Ant colonies usually consist of large numbers of workers and a single queen, who is the only female to reproduce. In most ant species, haploid males are produced asexually, whereas sex is used to produce diploid females that develop into either workers or new queens. Pearcy and colleagues found an intriguing difference from this reproductive strategy in the ant species Cataglyphia cursor.

C. cursor is one of a small number of ant species in which unmated workers occasionally reproduce through a process known as automictic thelytokous parthenogenesis to produce females from an unfertilized egg. This involves meiosis, followed by fusion of two of the haploid products to produce diploid offspring. The authors studied the genetic makeup of 38 colonies of C. cursor, genotyping 4 highly polymorphic microsatellite markers in 532 workers. They found that a large majority of workers are produced by sexual reproduction, with only a small proportion being produced asexually. Unexpectedly, however, genotyping 56 new queens from different colonies showed that almost all were the result of automictic

\section{(1) References and links}

ORIGINAL RESEARCH PAPER Ronshaugen, M. \& Levine, M. Visualization of trans-homolog enhancer-promoter interactions at the Abd-B Hox locus in the Drosophila embryo. Dev. Cell 7 , 925-932 (2004)

WEB SITE

Mike Levine's laboratory:

http://mcb.berkeley.edu/faculty/GEN/levinem.html

parthenogenesis by a queen - a different situation to most species, in which new queens are produced sexually.

The production of new queens in this way leads to a high degree of relatedness between queens and a high level of homozygosity that might be expected to reduce queen survival. However, unlike other species, where new queens set up new colonies on their own, in C. cursor they mate before they leave their colony and take adult workers with them. So, the authors suggest that optimum fitness among queens is less crucial than in other species. This allows genetic diversity to be maintained in the colony through sex, while the queen maximizes the propagation of her own genes through the asexual production of her successors.

This study illustrates the diversity of reproductive strategies among social insects - a feature that can provide important insights into the relative merits of sexual and asexual reproduction.

Louisa Flintoft

\section{(9) References and links}

ORIGINAL RESEARCH PAPER

Pearcy, M., Aron, S., Doums, C. \& Keller, L. Conditional use of sex and parthenogenesis for worker and queen production in ants. Science 306, 1780-1783 (2004)

FURTHER READING

Otto, S. P. \& Lenormand, T. Resolving the paradox of sex and recombination. Nature Rev. Genet. 3, 252-261 (2002) WEB SITE

Serge Aron's Laboratory:

http://www.ulb.ac.be/sciences/ecoevol/index.html 